\begin{tabular}{|ll}
$\begin{array}{l}\text { Evidence-Based } \\
\text { Decision Making } \\
\text { in Dentistry }\end{array}$ & $\begin{array}{l}\text { EVIDENCE-BASED DECISION MAKING IN } \\
\text { DENTISTRY }\end{array}$ \\
& $\begin{array}{l}\text { Eyal Rosen, Carlos E. Nemcovsky, Igor Tsesis } \\
\text { 2017, Springer } \\
\text { price } \mathrm{f} 82 \mathrm{pp} 141 \\
\text { ISBN: } 9783319457314\end{array}$ \\
\end{tabular}

Treatment planning for the adult dentition is a routine task for all general dental practitioners. A common clinical predicament is to consider the loss versus restoration of a natural tooth. Evidencebased decision making in dentistry: multidisciplinary management of the natural dentition aims to aid implementing evidence-based decision making with regards to restorative management of the natural dentition. The intended audience of this book is the general dental practitioner, aiming to provide knowledge and a skill set for clinical scenarios.

The book begins explaining evidence-based dentistry as a concept, and how to effectively understand and evaluate literature. This aspect of the book is a useful starting point for practitioners that may have turned to literature to aid their clinical understanding, but are not sure on how to appraise the validity of the information. The book, in turn, then moves on to discuss endodontic, periodontal and restorative decision-making processes, the use of cone beam CT and advancing treatment options such as bone regeneration. Each chapter is in journal article format, each with a comprehensive list of references. The book covers a wide variety of content of areas within dentistry, and intersperses fundamental knowledge with more complex components. There are multiple clinical cases with corresponding images which supplement the text well.

In summary, the book provides an overview of factors to consider when treatment planning the adult dentition. The book gives good 'food for thought' of treatment possibilities in an ever-evolving speciality. On the whole, I think the book is aimed appropriately to its target audience. Particularly, the chapters on restorative management and implant placement are useful to aid case planning for general dental practitioners and mature undergraduate students. While the content of the book does perhaps not aid general dentists in routine daily treatment, it gives insight and sparks interest in treatment possibilities available within wider clinical networks. It gives a broad overview of multiple topics, providing a platform for the reader to then further consult the available literature.

Available to buy from the BDA shop: https://shop.bda.org

\section{Free resources on oral health during pregnancy}

The European Federation of Periodontology (EFP) has launched a campaign to highlight the importance of oral health for pregnant women and for its possible impact on delivery.

Scientific reports, practical guidelines, infographics and other materials are freely available for dental practices, gynaecologists, midwives, physicians, pharmacists, health organisations, and the general public.

A special website has been created to help all 30 EFP-affiliated national societies of periodontology to raise awareness of pregnancy gingivitis and its implications among dentistry professionals, other health professionals, and women: http://www.efp.org/publications/ projects/oralhealthandpregnancy/.

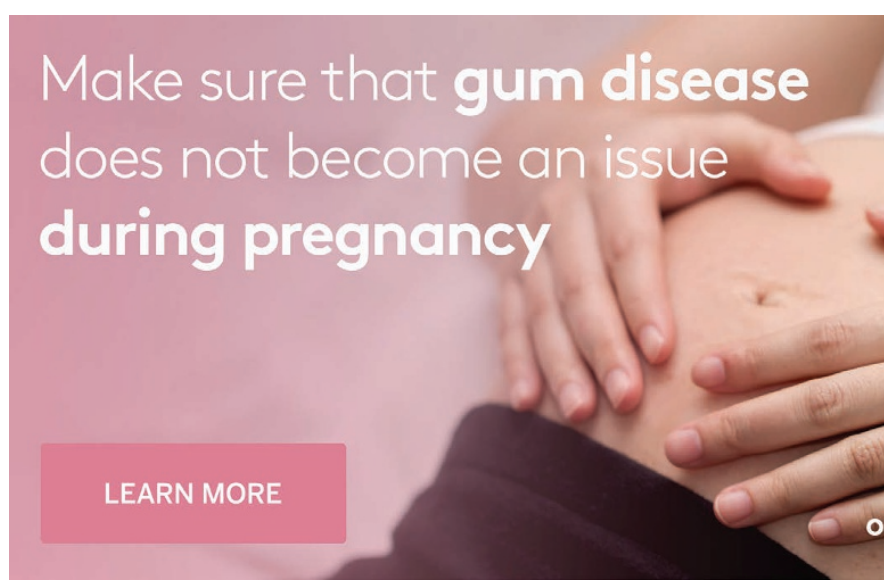

\section{Funding fair for potential PhD students}

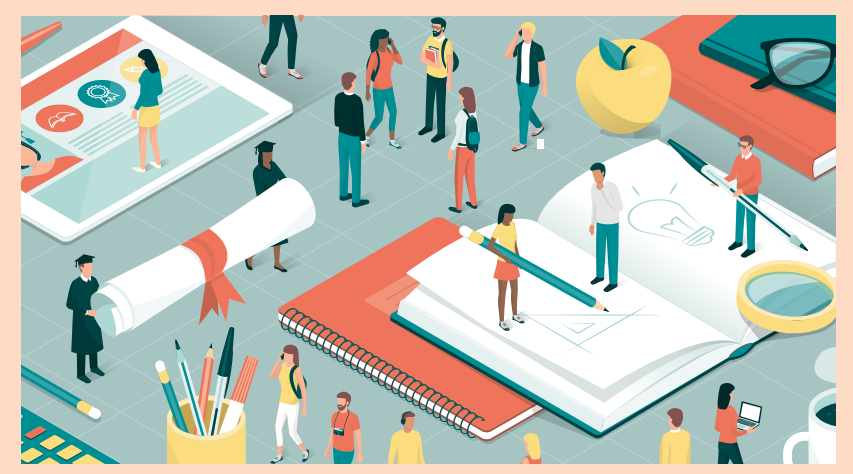

The annual PostgraduateStudentships PhD Funding Fair will be held on 4 December 2017 in Central London. This is a free event dedicated to and focusing on the needs of potential $\mathrm{PhD}$ students, enabling attendees to:

- Meet high quality universities with $\mathrm{PhD}$ funding

- Chat to current PhD students about looking for and doing a PhD

- Attend talks on how to apply for a $\mathrm{PhD}$ and find funding.

In order to attend, students need to apply and be accepted. All applicants are also entered into a prize draw to win a $\mathrm{PhD}$ study skills book called How to get a PhD.

More details and an application form to attend can be found at www.postgraduatestudentships.co.uk/ postgraduatestudentships-phd-funding-fair. 